\title{
Intercomparison of nitrous acid (HONO) measurement techniques in a megacity (Beijing)
}

\author{
Leigh R. Crilley ${ }^{1}$, Louisa J. Kramer ${ }^{1}$, Bin Ouyang ${ }^{2}$, Jun Duan ${ }^{3}$, Wenqian Zhang ${ }^{4}$, Shengrui Tong ${ }^{4}$, Maofa Ge ${ }^{4}$, \\ Ke Tang ${ }^{3}$, Min Qin ${ }^{3}$, Pinhua Xie ${ }^{3}$, Marvin D. Shaw ${ }^{5,6}$, Alastair C. Lewis ${ }^{5,6}$, Archit Mehra ${ }^{7}$, Thomas J. Bannan ${ }^{7}$, \\ Stephen D. Worrall ${ }^{7, a}$, Michael Priestley ${ }^{7, b}$, Asan Bacak ${ }^{7}$, Hugh Coe $^{7}$, James Allan ${ }^{7,6}$, Carl J. Percival ${ }^{7, c}$, \\ Olalekan A. M. Popoola ${ }^{8}$, Roderic L. Jones ${ }^{8}$, and William J. Bloss ${ }^{1}$ \\ ${ }^{1}$ School of Geography, Earth and Environmental Science, University of Birmingham, Edgbaston, \\ Birmingham, B15 2TT, UK \\ ${ }^{2}$ Lancaster Environment Centre, Lancaster University, Lancaster, LA1 4YQ, UK \\ ${ }^{3}$ Key Laboratory of Environment Optics and Technology, Anhui Institute of Optics and Fine Mechanics, \\ Chinese Academy of Sciences, Hefei, 230031, China \\ ${ }^{4}$ Beijing National Laboratory for Molecular Sciences (BNLMS), State Key Laboratory for Structural Chemistry of Unstable \\ and Stable Species, CAS Research/Education Center for Excellence in Molecular Sciences, Institute of Chemistry, \\ Chinese Academy of Sciences, Beijing 100190, China \\ ${ }^{5}$ Wolfson Atmospheric Chemistry Laboratories, University of York, Heslington, York, YO10 5DD, UK \\ ${ }^{6}$ National Centre for Atmospheric Science, UK \\ ${ }^{7}$ Centre for Atmospheric Science, School of Earth and Environmental Sciences, University of Manchester, \\ Manchester, M13 9PL, UK \\ ${ }^{8}$ Department of Chemistry, University of Cambridge, Cambridge, CB2 1EW, UK \\ ${ }^{a}$ now at: Chemical Engineering and Applied Chemistry, School of Engineering and Applied Sciences, \\ Aston University, Birmingham, B4 7ET, UK \\ bnow at: Atmospheric Science, Department of Chemistry and Molecular Biology, University of Gothenburg, \\ Gothenburg, Sweden \\ ${ }^{c}$ now at: Jet Propulsion Laboratory, 4800 Oak Grove Drive, Pasadena, CA 91109, USA
}

Correspondence: William J. Bloss (w.j.bloss@bham.ac.uk)

Received: 4 April 2019 - Discussion started: 15 May 2019

Revised: 9 October 2019 - Accepted: 29 October 2019 - Published: 9 December 2019

\begin{abstract}
Nitrous acid (HONO) is a key determinant of the daytime radical budget in the daytime boundary layer, with quantitative measurement required to understand $\mathrm{OH}$ radical abundance. Accurate and precise measurements of $\mathrm{HONO}$ are therefore needed; however HONO is a challenging compound to measure in the field, in particular in a chemically complex and highly polluted environment. Here we report an intercomparison exercise between HONO measurements performed by two wet chemical techniques (the commercially available a long-path absorption photometer (LOPAP) and a custom-built instrument) and two broadband cavityenhanced absorption spectrophotometer (BBCEAS) instruments at an urban location in Beijing. In addition, we re-
\end{abstract}

port a comparison of HONO measurements performed by a time-of-flight chemical ionization mass spectrometer (ToFCIMS) and a selected ion flow tube mass spectrometer (SIFTMS) to the more established techniques (wet chemical and BBCEAS). The key finding from the current work was that all instruments agree on the temporal trends and variability in HONO $\left(r^{2}>0.97\right)$, yet they displayed some divergence in absolute concentrations, with the wet chemical methods consistently higher overall than the BBCEAS systems by between $12 \%$ and $39 \%$. We found no evidence for any systematic bias in any of the instruments, with the exception of measurements near instrument detection limits. The causes of the divergence in absolute HONO concentrations were unclear, 
and may in part have been due to spatial variability, i.e. differences in instrument location and/or inlet position, but this observation may have been more associative than casual.

\section{Introduction}

Nitrous acid (HONO) is one of the key daytime sources of radicals in the boundary layer, and as it readily undergoes photolysis to form the $\mathrm{OH}$ radical, the contribution of $\mathrm{HONO}$ photolysis to the $\mathrm{OH}$ budget can be significant in megacities, up to $33 \%$ in Beijing (Yang et al., 2014) and $40 \%$ in London (Lee et al., 2016) as well as in forest (33\%, Kleffmann et al., 2005) and rural areas (42\%, Acker et al., 2006). The $\mathrm{OH}$ radical is the primary oxidant in the troposphere that drives chemical processing, principally the oxidation of volatile organic compounds (VOCs) that lead to the formation of ozone and secondary organic aerosols. There are a number of known sources of HONO including direct emissions, heterogeneous reactions, homogenous gasphase reactions, biological processes and surface photolysis (see reviews by Lammel and Cape, 1996; Kleffmann, 2007; Spataro and Ianniello, 2014), and recently abiotic and biotic processes on soils and biocrusts (Weber et al., 2015; Kim and Or, 2019). Across urban areas, high-spatial heterogeneity in HONO concentration can be observed depending on the proximity to direct emission sources of HONO (Crilley et al., 2016; Lee et al., 2013). Despite the importance of HONO to the overall radical budget, the contributions of these different sources, particularly in the urban environment, are poorly understood (See e.g. Lee et al., 2016; Michoud et al., 2014).

As a result of the significance of HONO to tropospheric photochemistry, accurate and precise concentration measurements are required but are challenging due to a number of known potential artefacts in the available approaches. Positive artefacts can occur in inlet lines, as HONO is easily formed through heterogeneous reactions on wet surfaces (Zhou et al., 2002). Furthermore, the highly reactive nature of HONO means that within inlet lines, wall interactions could also lead to a negative artefact unless inert materials are employed (Pinto et al., 2014). Other challenges include interferences from species such as $\mathrm{NO}_{2}$. There are a number of approaches to measure HONO that can be classed as either wet chemical spectroscopic techniques or offline methods (Spataro and Ianniello, 2014). Some of the main instrumentation used recently to measure ambient HONO in the literature include differential optical absorption spectroscopy (DOAS, e.g. Perner and Platt, 1979), wet chemical techniques (e.g. long-path absorption photometer (LOPAP), Heland et al., 2001), broadband cavity-enhanced absorption spectroscopy (e.g. Duan et al., 2018), soft chemical ionization mass spectrometry (CIMS, e.g. Veres et al., 2015), online ion chromatography (e.g. Stutz et al., 2010; Cheng et al., 2013) and wet denuder (e.g. Acker et al., 2004). In order to compare reported measurements across studies, it is necessary to understand how the different approaches or techniques compare relative to each other, under actual ambient (field) conditions.

There have been a number of studies reporting intercomparisons between HONO instrumentation (e.g. Stutz et al., 2010; Ródenas et al., 2013; Pinto et al., 2014; Kleffmann et al., 2006). Generally, HONO measurements by DOAS systems are used as a reference during intercomparison studies, as optical methods are artefact free with respect to sampling method, though impurities in the $\mathrm{HONO}$ and $\mathrm{NO}_{2}$ reference spectra can affect retrievals (Stutz et al., 2010; Kleffmann et al., 2006). A further complication with using DOAS systems as a reference is that the spatial averaging inherent in the system means that comparison with point measurements may be subject to bias due to spatial heterogeneities in HONO concentrations. Typically, most in situ instruments report higher concentrations during the day compared to simultaneous measurements by a DOAS system, thought to be due to the positive interferences in the in situ techniques (see e.g. Febo et al., 1996; Appel et al., 1990; Stutz et al., 2010; Spindler et al., 2003). An exception is the work by Kleffmann et al. (2006), who reported excellent agreement between a LOPAP and DOAS system in both chamber-based and field measurements of HONO under both day and night conditions. The reason for the better performance of the LOPAP is the two-channel stripping coil employed in the LOPAP successfully corrects for positive artefacts and chemical interferents during measurement, as demonstrated by Kleffmann et al. (2008).

Recently, there have been multi-instrumental intercomparison studies performed in ambient air and in simulation chambers. These include the Formal Intercomparison of Observations of Nitrous Acid (FIONA) project, which involved 18 instruments measuring within the European Photoreactor (EUPHORE) chamber over a wide range of HONO concentrations (Ródenas et al., 2013). While in general, good agreement was observed during the different experiments of FIONA, at high concentrations ( $>15 \mathrm{ppb}$ ) divergence was observed between some instruments possibly due to some instruments experiencing saturation (Ródenas et al., 2013). These high HONO concentrations, however, are not typical even in highly polluted locations like Beijing (Tong et al., 2016; Wang et al., 2017). Pinto et al. (2014) described an intercomparison of field measurements performed in Houston using a number of instruments for measuring HONO. The instruments tested included a long-path DOAS, a number of wet chemical (including a LOPAP), online ion chromatography and a time-of-flight chemical ionization mass spectrometer (ToF-CIMS) using iodide as a reagent ion CIMS. Overall, while good agreement between all the instruments was observed in terms of the temporal trends, the absolute concentrations varied. Pinto and co-workers were unable to pinpoint the cause of the disagreement in absolute concentrations, but they speculated it might have been due to chemical interfer- 
ence in the in situ techniques and the effect of heterogeneous surface reactions due to the distance between some inlets.

Here, we report an intercomparison exercise of co-located wet chemical and broadband cavity-enhanced absorption spectrophotometer (BBCEAS) instruments for measuring HONO in an urban location within Beijing. Ambient concentrations of HONO can vary by several orders of magnitude in Beijing, up to $9 \mathrm{ppb}$ during haze events with a typical concentration of $1.44 \pm 1.33 \mathrm{ppb}$ (Wang et al., 2017), making it a challenging location for field measurements. In addition, we report a comparison of HONO retrievals by a ToF-CIMS and selected ion flow tube mass spectrometer (SIFT-MS) to the more established techniques (wet chemical and BBCEAS) for measuring HONO. Based on the intercomparison findings, the factors that may have influenced the measured concentrations are investigated.

\section{Method}

\subsection{Site description}

Measurements were performed as part of the Air Pollution and Human Health in a Chinese megacity (APHH-Beijing, http://www.aphh.org.uk, last access: 26 November 2019) programme and of the "An integrated study of air pollution processes in Beijing" (AIRPRO) project, which aimed to understand atmospheric processes affecting air pollution in Beijing. An overview of the APHH-Beijing project is provided in Shi et al. (2019). Measurements were performed at the Chinese Academy of Sciences' Institute of Atmospheric Physics (IAP) tower campus, an urban site located near the 4th ring road in the northern suburbs of Beijing. There were two field campaigns, the first took place during NovemberDecember 2016 (referred to as winter) and second during May-June 2017 (referred to as summer).

\subsection{Instrument descriptions}

An overview of all the instruments that measured groundlevel HONO at IAP is provided in Table 1. As instruments of the same type were used in this study, throughout this paper the instruments will be referred to by their institution name, as per Table 1. A brief description of each instrument follows.

\subsubsection{University of Birmingham LOPAP}

The University of Birmingham operated a LOPAP (QUMA Elektronik \& Analytik GmbH) at IAP. The LOPAP is a wet chemical technique and has been described in detail in Heland et al. (2001) and Kleffmann et al. (2002). Briefly, a stripping coil is used to sample gas-phase HONO into an acidic solution where it is derivatized into an azo dye. The light absorption of the azo dye, principally at $550 \mathrm{~nm}$ (though higher wavelengths can also be used), is then measured with a spectrometer using an optical path length of $2.4 \mathrm{~m}$. The LOPAP was operated and calibrated according to the standard procedures described in Kleffmann et al. (2008). The time resolution of the LOPAP was $5 \mathrm{~min}$ and baseline measurements were taken at frequent intervals $(8 \mathrm{~h})$. The operationally defined detection limit $(2 \sigma)$ of the LOPAP was calculated to be 35 and $5 \mathrm{ppt}$ for winter and summer, respectively and varied due to changes in purity of reagents and zero air used. The LOPAP was housed within a temperature controlled shipping container and sampled at a height of $3 \mathrm{~m}$ above ground level.

\subsubsection{Institute of Chemistry, Chinese Academy of Sciences wet chemical HONO analyser}

Institute of Chemistry, Chinese Academy of Sciences (ICCAS) applied a custom-built instrument, described in detail elsewhere (Hou et al., 2016). It is a wet chemical technique similar in principle to the LOPAP. Gas-phase HONO is almost completely absorbed by an absorption solution into a two-channel stripping coil, where it forms an azo dye, detected by absorption spectroscopy at a wavelength of $550 \mathrm{~nm}$ with an optical path length of $0.5 \mathrm{~m}$. The instrument has a detection limit $(2 \sigma)$ of $134 \mathrm{ppt}$ for a response time of $5 \mathrm{~min}$. The ICCAS and BHAM instruments both used a similar outdoor sampling unit that employed a short quartz inlet $(<2.5 \mathrm{~cm})$. While the BHAM and ICCAS instruments operated according to the same principles, there were two main differences. The first was the method for determining the baseline, the BHAM instrument used an overflow of $\mathrm{N}_{2}$ while the ICCAS instrument replaced the reagents with water. The second was the optical path length, which was 2.0 and $0.5 \mathrm{~m}$ for the BHAM and ICCAS instruments, respectively.

\subsubsection{University of Cambridge BBCEAS}

The University of Cambridge ran a three-channel BBCEAS instrument during the campaign, with one channel measuring $\mathrm{NO}_{2}$ and $\mathrm{HONO}$ simultaneously in the UV (362-374 nm) wavelength region. Reference absorption cross sections of HONO (Stutz et al., 2000) and $\mathrm{NO}_{2}$ (Voigt et al., 2002) were fitted to the absorption coefficient to retrieve $\mathrm{HONO}$ and $\mathrm{NO}_{2}$ concentrations. Details of the instrument can be found in Kennedy et al. (2011). Two mirrors (Layertec 109053) with peak reflectivity of $\sim 99.95 \%$ at $365 \mathrm{~nm}$ were used to form the cavity. Given an inter-mirror distance of $92 \mathrm{~cm}$, the effective absorption pathlength in the case of an empty cavity was around $1.8 \mathrm{~km}$. Both the instrument inlet and the optical cavity were made of perfluoroalkoxy alkane (PFA) which is well known for its chemical inertness. The inlet line was $1 / 4 \mathrm{in}$. outer diameter PFA tubing and was approximately $3 \mathrm{~m}$ long. During the winter phase of the campaign, instrument inlet was placed at the top of the container and was about $3 \mathrm{~m}$ from the ground. During the summer phase however, the instrument was moved to an adjacent container, also housing the other BBCEAS instrument, and the height of instrument inlet was changed accordingly from $\sim 3$ to $\sim 2 \mathrm{~m}$. 
Table 1. Instrumentation measuring HONO at IAP.

\begin{tabular}{|c|c|c|c|c|c|c|}
\hline Institution & Instrument & Manufacturer & $\mathrm{DL}(\mathrm{ppt})$ & Error & Time resolution & Reference \\
\hline $\begin{array}{l}\text { Birmingham } \\
\text { (BHAM) }\end{array}$ & $\begin{array}{l}\text { wet } \\
\text { chemical } \\
\text { (LOPAP.03) }\end{array}$ & QUMA & $\begin{array}{l}\text { winter: } 35 \\
\text { summer: } 5 \\
(2 \sigma, 30 \mathrm{~s})\end{array}$ & $10 \%$ & $5 \mathrm{~min}$ & Heland et al. (2001) \\
\hline ICCAS & $\begin{array}{l}\text { wet } \\
\text { chemical }\end{array}$ & custom built & $\begin{array}{l}134 \\
(2 \sigma, 30 \mathrm{~s})\end{array}$ & $10 \%$ & $5 \mathrm{~min}$ & Hou et al. (2016) \\
\hline $\begin{array}{l}\text { Cambridge } \\
\text { (CAM) }\end{array}$ & BBCEAS & custom built & $\begin{array}{l}25 \\
(1 \sigma, 60 s)\end{array}$ & $9 \%$ & $5 \mathrm{~s}$ & Kennedy et al. (2011) \\
\hline AIOFM & BBCEAS & custom built & $\begin{array}{l}120 \\
(2 \sigma, 60 s)\end{array}$ & $9 \%$ & $1 \mathrm{~min}$ & Duan et al. (2018) \\
\hline $\begin{array}{l}\text { Manchester } \\
\text { (MANC) }\end{array}$ & ToF-CIMS & $\begin{array}{l}\text { Aerodyne } \\
\text { Research Inc/ } \\
\text { Tofwerk }\end{array}$ & $\begin{array}{l}33 \\
(2 \sigma, 60 s)\end{array}$ & $19 \%$ & $1 \mathrm{~Hz}$ & Priestley et al. (2018) \\
\hline York & $\begin{array}{l}\text { SIFT-MS } \\
\text { Voice ultra } \\
200\end{array}$ & $\begin{array}{l}\text { Syft } \\
\text { Technologies }\end{array}$ & $\begin{array}{l}130 \\
(2 \sigma, 60 \mathrm{~s})\end{array}$ & $22 \%$ & $\begin{array}{l}19 \mathrm{~s} \\
(1 \mathrm{~min} \\
\text { averaged })\end{array}$ & Hera et al. (2018) \\
\hline
\end{tabular}

To allow a more stable cavity throughput (i.e. to minimize flow turbulence effect on the optical signal), the sampling flow was set to $2 \mathrm{~L} \mathrm{~min}^{-1}$ for the $\mathrm{HONO} / \mathrm{NO}_{2}$ measurement channel. This was close to the very low end of the operational range of the flow controller $\left(0-50 \mathrm{~L} \mathrm{~min}^{-1}\right)$, leading to the actual flow rate potentially differing from that set. Postcampaign analysis identified that this affected both the dilution factor (dilution of the sample flow by the two mirror purge lines) and the length the sample gas occupied the cavity. A post-campaign calibration was therefore performed by injecting a known amount of $\mathrm{NO}_{2}$ into the cavity under otherwise identical operating conditions, and a scaling factor of $\sim 1.27$ was found to be necessary to account for these two factors and was then applied to the measured $\mathrm{NO}_{2}$ and HONO concentrations.

\subsubsection{Anhui Institute of Optics and Fine Mechanics BBCEAS}

The custom-built BBCEAS instrument from the Anhui Institute of Optics and Fine Mechanics (AIOFM), Chinese Academy of Sciences, has been described in detail in Duan et al. (2018); therefore only a brief description is given here. Light is emitted by a single light-emitting diode (LED) with peak wavelength of $365 \mathrm{~nm}$, full width at half maximum (FWHM) of $13 \mathrm{~nm}$ and is introduced into the resonant cavity, consisting of a pair of high-reflective (HR) mirrors with reflectivity of about 0.99985 at $368 \mathrm{~nm}$, separated by $55.0 \mathrm{~cm}$. The emergent light intensity passing through the cavity exit mirror is received by an Ocean Optics QE65000 spectrometer through an optical fibre with $600 \mu \mathrm{m}$ diameter and a 0.22 numerical aperture.
In order to avoid the drift of the centre wavelength of the LED, the temperature of the LED was controlled to be approximately $20 \pm 0.05^{\circ} \mathrm{C}$ by using a thermoelectric cooler (TEC) unit. In order to prevent particulate matter from entering the cavity and reducing the effect of particulate matter on the effective absorption path, a $1 \mu \mathrm{m}$ PTFE filter membrane (Tisch Scientific) was used in the front end of the sampling port. The time resolution of the BBCEAS instrument was $1 \mathrm{~min}$, and the $2 \sigma$ detection limit of $\mathrm{HONO}$ was about 120 pptv. The fitting wavelength range was selected as 359$387 \mathrm{~nm}$, with the same reference cross sections used in the retrieval of $\mathrm{NO}_{2}$ and HONO as for the University of Cambridge instrument. Sample loss and secondary formation of HONO were both considered in this instrument and the measurement error of HONO was estimated to be approximately $9 \%$. The inlet line was $1 / 4$ in. outer diameter PFA tubing and was approximately $4 \mathrm{~m}$ long.

\subsubsection{University of Manchester ToF-CIMS}

A time-of-fight chemical ionization mass spectrometer (ToF-CIMS) (Lee et al., 2014), using an iodide ionization system was coupled with a filter inlet for gases and aerosols (FIGAERO) originally developed by Lopez-Hilfiker et al. (2014) and recently described and characterized by Bannan et al. (2019). The detailed setup during this campaign can be found in Zhou et al. (2018). The FIGAERO enabled near simultaneous, real-time measurements of both the gas and particle phase composition. Only gas-phase data are presented here, so with every $75 \mathrm{~min}$ of continuous data $35 \mathrm{~min}$ (particle phase mode) are omitted. The gas-phase inlet consisted of $5 \mathrm{~m} 1 / 4 \mathrm{in}$. I.D. PFA tubing connected to a fast inlet 
pump with a total flow rate of $13 \mathrm{slpm}$ (standard litres per minute) from which the ToF-CIMS sub-sampled 2 slpm.

Methyl iodide gas mixtures $\left(\mathrm{CH}_{3} \mathrm{I}\right)$ in $\mathrm{N}_{2}$ were made up in the field using a custom-made manifold (Bannan et al., 2014). A total of $20 \mathrm{sccm}$ (standard cubic centimetres per minute) of the $\mathrm{CH}_{3} \mathrm{I}$ mixture was diluted in $4 \mathrm{slpm} \mathrm{N}_{2}$ and ionized by flowing through a Tofwerk X-ray ionization source. This flow enters an ion molecule region (IMR), which was maintained at a pressure of 400 mbar using an SSH-112 pump fitted with an Aerodyne pressure control box to account for changes in ambient pressure. The IMR pressure is significantly higher than is usual for this CIMS instrument when using Po-210 but is necessary given the change in ionization source in this study. Operation is comparable to the Le Breton et al. (2018) study, who also used the same Tofwerk X-ray ionization source. A short segmented quadrupole (SSQ) was positioned behind the IMR and was held at a pressure of 2 mbar using a Tri scroll 600 pump.

The CIMS instrument zero was determined by flowing dry nitrogen into the IMR periodically, and the backgrounds were applied consecutively. As shown in Fig. S1 (Supplement), there was very little variability of this background during the measurement period. Though the overflowing of dry $\mathrm{N}_{2}$ will have an effect on the sensitivity of the instrument to those compounds whose detection is water dependent, due to the low instrument backgrounds, the absolute error remains small, and we deem this an acceptable limitation in order to measure a vast suite of different compounds for which no best practice backgrounding method has been established. We therefore calculated the absolute error of $33 \mathrm{ppt}$ as $3 \sigma$ deviations of the background signal.

Field calibrations were regularly carried out using known concentration formic acid gas mixtures made in the manifold. The instrument was calibrated for a range of other species after the campaign, and relative calibration factors were derived using the measured formic acid sensitivity as has been performed previously (Le Breton et al., 2014, 2017; Bannan et al., 2014, 2015). HONO was measured at $m / z 174$ as $\mathrm{I} \mathrm{HNO}_{2}^{-}$during the period of 27 May-17 June 2017. A stable and pure gas-phase source of HONO was generated for calibrations using the method described by Ren et al. (2010) and Febo et al. (1995), and a sensitivity of $0.28 \mathrm{cps} \mathrm{ppt}^{-1}$ was applied to the data with a limit of detection (LOD) of 33 ppt. Data analysis is performed using the "Tofware" package (version 2.5.11) running in the Igor Pro (WaveMetrics, OR, USA) environment. The mass axis was calibrated using $\mathrm{I}^{-}, \mathrm{I}_{2}^{-}$and $\mathrm{I}_{3}^{-}$. Extracted high-resolution time series were then normalized to the iodide reagent ion trace. A limitation of the CIMS calibration approach for HONO is that it was not established as a function of humidity. This was not deemed necessary because there was an average variation of only $2 \%$ in the $\mathrm{I}^{-}: \mathrm{IH}_{2} \mathrm{O}^{-}$ratio throughout the day.

\subsubsection{University of York SIFT-MS}

The data presented in this paper has been measured using a Voice200 Selected ion flow tube mass spectrometer (SIFTMS, Syft Technologies, Christchurch, New Zealand). This instrument consists of a switchable reagent ion source capable of rapidly switching between multiple reagent ions. The ion source region, where the reagent ions are generated in a microwave discharge, acts on an air-water mix at a pressure of approximately $440 \mathrm{mTorr}(1 \mathrm{mTorr}=0.133 \mathrm{~Pa})$ to generate the three reagent ions $\mathrm{H}_{3} \mathrm{O}^{+}, \mathrm{NO}^{+}$and $\mathrm{O}_{2}^{+}$. These ions are extracted into the upstream quadrupole chamber maintained at a pressure of approximately $5 \times 10^{-4}$ Torr, using a $70 \mathrm{~L} \mathrm{~s}^{-1}$ turbo-molecular pump. The reagent ions pass through an array of electrostatic lenses and the upstream quadrupole mass filter, and those not rejected by the mass filter are passed into the flow tube where they are carried along in a stream of nitrogen and selectively ionize target analytes. Gas-phase data presented herein were determined using the $\mathrm{H}_{3} \mathrm{O}^{+}$reagent ion only. Sampling was carried out at a height of $\sim 3 \mathrm{~m}$ using a gas-phase inlet consisting of $3.5 \mathrm{~m} 1 / 4$ in. I.D. PFA tubing connected to a diaphragm inlet pump (KNF) at a total flow rate of $5 \mathrm{slpm}$, from which the SIFT-MS sampled approximately $2 \mathrm{slpm}$ through an inhouse-built pressure-controlled inlet maintaining a consistent absolute inlet pressure of 0.5 bar. The flow tube is pumped by a $35 \mathrm{~m}^{3} \mathrm{~h}^{-1}$ scroll-type dry pump (Edwards) resulting in a mass flow controlled gas flow of $25 \mathrm{sccm}$ for the nitrogen carrier gas (research grade, BOC) and a sample flow of $100 \mathrm{sccm}$ from the pressure controlled inlet system. These flows result in a continuous total flow tube pressure of 460 mTorr and a reaction time of approximately $8 \mathrm{~ms}$ (Hera et al., 2018). During the campaign, gas-phase backgrounds were established through regularly overflowing the sample inlet with dry nitrogen for 5 continuous minutes every hour. The determined HONO gas-phase backgrounds in nitrogen were $110 \pm 40$ pptv during the measurement period presented, and as such are unlikely to have a significant contribution on the ambient mixing ratio.

The bimolecular reaction of $\mathrm{H}_{3} \mathrm{O}^{+}$and nitrous acid produces the product ions $\mathrm{H}_{2} \mathrm{NO}_{2}(m / z 48,67 \%)$ and $\mathrm{NO}^{+}$ $(\mathrm{m} / \mathrm{z} 30,33 \%)$. The rate constant $(k)$ of this exothermic proton transfer reaction is calculated to be $2.7 \times 10^{-9} \mathrm{~cm}^{3} \mathrm{~s}^{-1}$ with respect to hydronium $\left(\mathrm{H}_{3} \mathrm{O}^{+}\right)$and $2.2 \times 10^{-9} \mathrm{~cm}^{3} \mathrm{~s}^{-1}$ with respect to hydronium mono-hydrate $\left(\mathrm{H}_{3} \mathrm{O} \cdot \mathrm{H}_{2} \mathrm{O}\right)^{+}$ (Spanel and Smith, 2000). Nitrous acid does not undergo proton transfer with hydronium di-hydrate $\left(\mathrm{H}_{3} \mathrm{O} \cdot \mathrm{H}_{2} \mathrm{O}^{2}\right)^{+}$and tri-hydrate $\left(\mathrm{H}_{3} \mathrm{O} \cdot \mathrm{H}_{2} \mathrm{O}^{3}\right)^{+}$in SIFT-MS. Nitrous acid mixing ratios herein were determined using the branching-ratiocorrected protonated product ion $\mathrm{m} / \mathrm{z} 48$ intensity normalized to both $\mathrm{H}_{3} \mathrm{O}^{+}$and $\mathrm{H}_{3} \mathrm{O} \cdot \mathrm{H}_{2} \mathrm{O}$ with their respective $k$ values (Taipale et al., 2008). As such, calculated HONO mixing ratios using SIFT-MS should be independent of the humidity of the gas sample. 


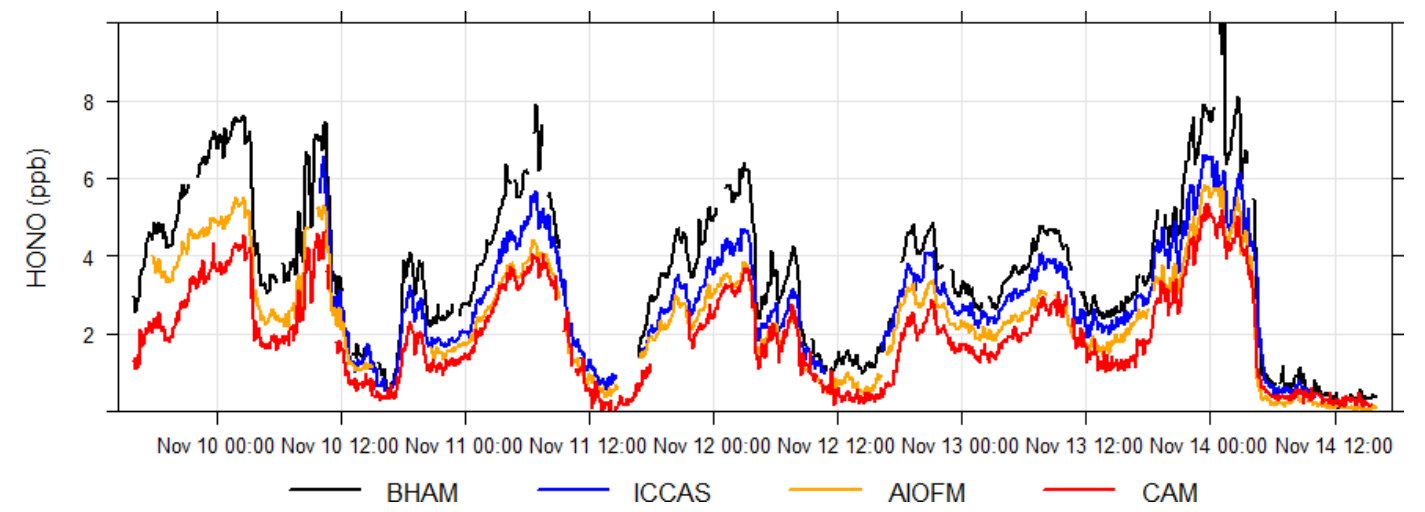

Figure 1. Time series of the measured mixing ratios during the formal winter intercomparison for each instrument. Time zone is local time, China standard time (CST).

\subsection{Formal intercomparison}

The formal intercomparison of the four established techniques for measuring HONO (two wet chemical and two BBCEAS) took place during 9-14 November 2016. All instruments had a sampling height of $3 \mathrm{~m}$ during the intercomparison, and inlets were located as close as possible to each other (Fig. S2). The BHAM and ICCAS instruments were housed within the same shipping container, with their respective inlet heads located beside each other on the roof. The CAM and AIOFM BBCEAS instruments were housed in separate containers, with inlets located approximately 5 and $10 \mathrm{~m}$, respectively, from the two wet chemical inlet heads. On the completion of the formal winter intercomparison, the inlet locations changed for some of the instruments.

There was no formal intercomparison between all four instruments in the summer campaign. The BHAM, CAM and ICCAS inlets were located in the same position as per the winter intercomparison at the start (22 May-30 June 2017). Therefore, further analysis was performed between these three instruments for this period to examine for any changes in their relationships compared to the winter measurements. The AIOFM instrument was housed within the same container as per the winter, however the inlet was located approximately $3 \mathrm{~m}$ further away from other instruments in the summer. On the 30 May, the CAM instrument was moved to the same container as the AIOFM, with the inlets located approx. $3 \mathrm{~m}$ from each other.

The ToF-CIMS and SIFT-MS were not initially set up to measure HONO at IAP but were able to provide some useful data during the summer measurements and are therefore compared to the more established techniques. A schematic of inlet locations during the summer campaign is provided in Fig. S3.

\subsection{Data analysis}

The BHAM and ICCAS instruments were operated with a time response of $5 \mathrm{~min}$, and as this was the longest (Table 1)
5 min averages were used for all instruments in the intercomparison analyses. For each instrument, their normal quality control procedures were applied and only data that passed the quality control was used for subsequent analysis. Data analysis was performed in $\mathrm{R}$ ( $\mathrm{v}$ 3.5.1) using the openair package (Carslaw and Ropkins, 2012) and the lmodel 2 package for reduced major axis (RMA) regression analysis.

\section{Results}

\subsection{Winter formal intercomparison}

\subsubsection{Time series}

The time series (Fig. 1) demonstrates that while all instruments captured the same temporal trends, the absolute concentrations differed. The correlation coefficients from regression analyses show that there is little scatter between measurements from the different instruments with $r$ values being consistently between 0.96 and 0.98 (Table 2 and Fig. S4). Overall, the BHAM LOPAP measurements were consistently the highest, followed by ICCAS, AIOFM and CAM. The slopes from the RMA analysis demonstrated that none of the instruments were in agreement (Table 2) within their stated error (Table 1) during the formal intercomparison exercise. Therefore, in the following sections we investigate possible reasons to account for the lack of agreement between instruments.

\subsubsection{Analysis of coefficient of variance}

We calculated the coefficient of variance (CV) as a measure of the precision between the four instruments as per Eq. (1):

$\mathrm{CV}=\frac{\sigma}{\mu}$,

where $\mu$ is the mean and $\sigma$ is the standard deviation for the measurements by all four instruments at a given $5 \mathrm{~min}$ interval. The $\mathrm{CV}$ was used to compare the relative degree of 
Table 2. Results of the reduced major axis regression analysis with $95 \%$ confidence intervals during the formal winter intercomparison. Variability shown is the $95 \%$ confidence interval of the slope and intercepts.

\begin{tabular}{lrccc}
\hline Instruments & Intercept & Slope & $R$ & $N$ \\
\hline BHAM-ICCAS & $0.09 \pm 0.04$ & $0.77 \pm 0.01$ & 0.97 & 865 \\
BHAM-AIOFM & $-0.18 \pm 0.03$ & $0.71 \pm 0.01$ & 0.98 & 1070 \\
BHAM-CAM & $-0.23 \pm 0.03$ & $0.61 \pm 0.01$ & 0.98 & 1125 \\
ICCAS-AIOFM & $-0.20 \pm 0.03$ & $0.88 \pm 0.01$ & 0.98 & 954 \\
ICCAS-CAM & $-0.38 \pm 0.04$ & $0.82 \pm 0.01$ & 0.97 & 991 \\
AIOFM-CAM & $-0.09 \pm 0.03$ & $0.87 \pm 0.01$ & 0.96 & 1206 \\
\hline
\end{tabular}

variation between datasets and as a guide a CV of 0.1 is considered as acceptable by the US EPA for particulate matter PM instruments (Sousan et al., 2016). From Fig. 2, the $\mathrm{CV}$ was fairly consistent throughout the winter intercomparison, at an average of $0.28 \pm 0.07$. The $\mathrm{CV}$ was however observed to increase at the end of the intercomparison, coinciding with period of the lowest mean HONO concentration ( $<1 \mathrm{ppb}$, Fig. 2). An increase in the CV indicates worsening agreement between instruments, possibly due to the concentrations approaching the detection limit (DL) of some instruments (Table 1) $\mathrm{NO}_{2}$ is a potential interferent for the measurement of HONO for both wet chemical and BBCEAS instruments (Heland et al., 2001). Both BBCEAS instruments use the Voigt et al. (2002). $\mathrm{NO}_{2}$ cross section, which has previously been shown to have negligible HONO absorption structures (Veitel, 2002; Kleffmann et al., 2006). We also note that $\mathrm{HONO}$ reference spectra should contain little structure from $\mathrm{NO}_{2}$. Overall, Fig. 2 demonstrates no apparent relationship between the $\mathrm{CV}$ and $\mathrm{NO}_{2}$. This likely reflects the efforts taken during processing and measurement to reduce the influence of interference from $\mathrm{NO}_{2}$ in all instrument types.

\subsubsection{Normalized difference analysis}

Firstly, the systematic error for each instrument can be calculated by normalized sequential difference (NSD) according to Eq. (2) (Arnold et al., 2007):

$\mathrm{NSD}=\frac{\left(\text { Conc }_{t}-\text { Conc }_{t+1}\right)}{\left(\text { Conc }_{t} \times \text { Conc }_{t+1}\right)^{0.5}}$.

NSD is a method of calculating the variation between consecutive measurements for an individual instrument, where Conc $_{t}$ is the concentration measured at time $\mathrm{t}$ and $\mathrm{Conc}_{t+1}$ the following measurement. The results are shown in Fig. S5, and as each instrument showed a symmetrical and Gaussian distribution it suggests there was no internal systematic bias for any given instrument.

Secondly, we then examined the normalized difference (ND) between pairs of instruments to explore interinstrument variability, calculated according to Eq. (3) (Pinto
Table 3. Calculated CD values for each instrument pair during the winter intercomparison.

\begin{tabular}{lrrr}
\hline & ICCAS & AIOFM & CAM \\
\hline BHAM & 0.11 & 0.22 & 0.32 \\
ICCAS & - & 0.12 & 0.21 \\
AIOFM & - & - & 0.11 \\
\hline
\end{tabular}

Table 4. RMA regression analysis (with $95 \%$ confidence intervals) for times when the abundance of HONO was less than $2 \mathrm{ppb}$ as measured by CAM during the formal winter intercomparison period. Variability shown is the $95 \%$ confidence interval of the slope and intercepts.

\begin{tabular}{lrccc}
\hline Instruments & Intercept & Slope & $R$ & $N$ \\
\hline BHAM-ICCAS & $-0.01 \pm 0.06$ & $0.82 \pm 0.02$ & 0.96 & 437 \\
BHAM-AIOFM & $-0.25 \pm 0.03$ & $0.76 \pm 0.01$ & 0.98 & 529 \\
BHAM-CAM & $-0.06 \pm 0.03$ & $0.53 \pm 0.01$ & 0.95 & 613 \\
ICCAS-AIOFM & $-0.23 \pm 0.05$ & $0.91 \pm 0.03$ & 0.95 & 478 \\
ICCAS-CAM & $-0.12 \pm 0.05$ & $0.68 \pm 0.02$ & 0.91 & 556 \\
AIOFM-CAM & $0.07 \pm 0.03$ & $0.72 \pm 0.02$ & 0.92 & 655 \\
\hline
\end{tabular}

et al., 2014):

$\mathrm{ND}_{i j}=\frac{\left(C_{i}-C_{j}\right)}{\left(C_{i}+C_{j}\right)}$,

where $C_{i}$ and $C_{j}$ denote HONO levels measured by any pair of instruments (BHAM, ICCAS, AIOFM or CAM) calculated for each measurement period. For example, the ND for the BHAM and CAM instruments (ND ${ }_{\text {BHAM-CAM }}$ ) would be calculated by ([HONO $]_{\mathrm{BHAM}^{-}}$ $\left.[\mathrm{HONO}]_{\mathrm{CAM}}\right) /\left([\mathrm{HONO}]_{\mathrm{BHAM}}+[\mathrm{HONO}]_{\mathrm{CAM}}\right)$. We also calculated the coefficient of divergence (CD), which is a normalized measure of the similarity between two measurement time series, derived via Eq. (4) (See Pinto et al. (2014) and references therein):

$\mathrm{CD}_{i j}=\sqrt{(1 / p) \times \sum\left(\mathrm{ND}_{i j}\right)^{2}}$,

where $p$ is the number of observations and $\mathrm{ND}_{i j}$ is defined in Eq. (3). A CD of 1 means the time series are completely different, while of $\mathrm{CD}$ of 0 indicates that they are identical. The calculated CD for each instrument pair is shown in Table 3 and demonstrates that each of the two overall approaches wet chemical (BHAM and ICCAS) and BBCEAS (AIOFM and CAM) - agreed well internally. The ICCAS and AIOFM also agreed well, but CAM and BHAM had a higher $\mathrm{CD}$ with AIOFM and ICCAS (Table 3).

If there is no difference between a pair of instruments, then the calculated ND should be scattered around 0 , and from Fig. 3 this was not observed for any instrument pair, pointing to differences between instruments. The ND was evaluated as function of wind direction and measured HONO 

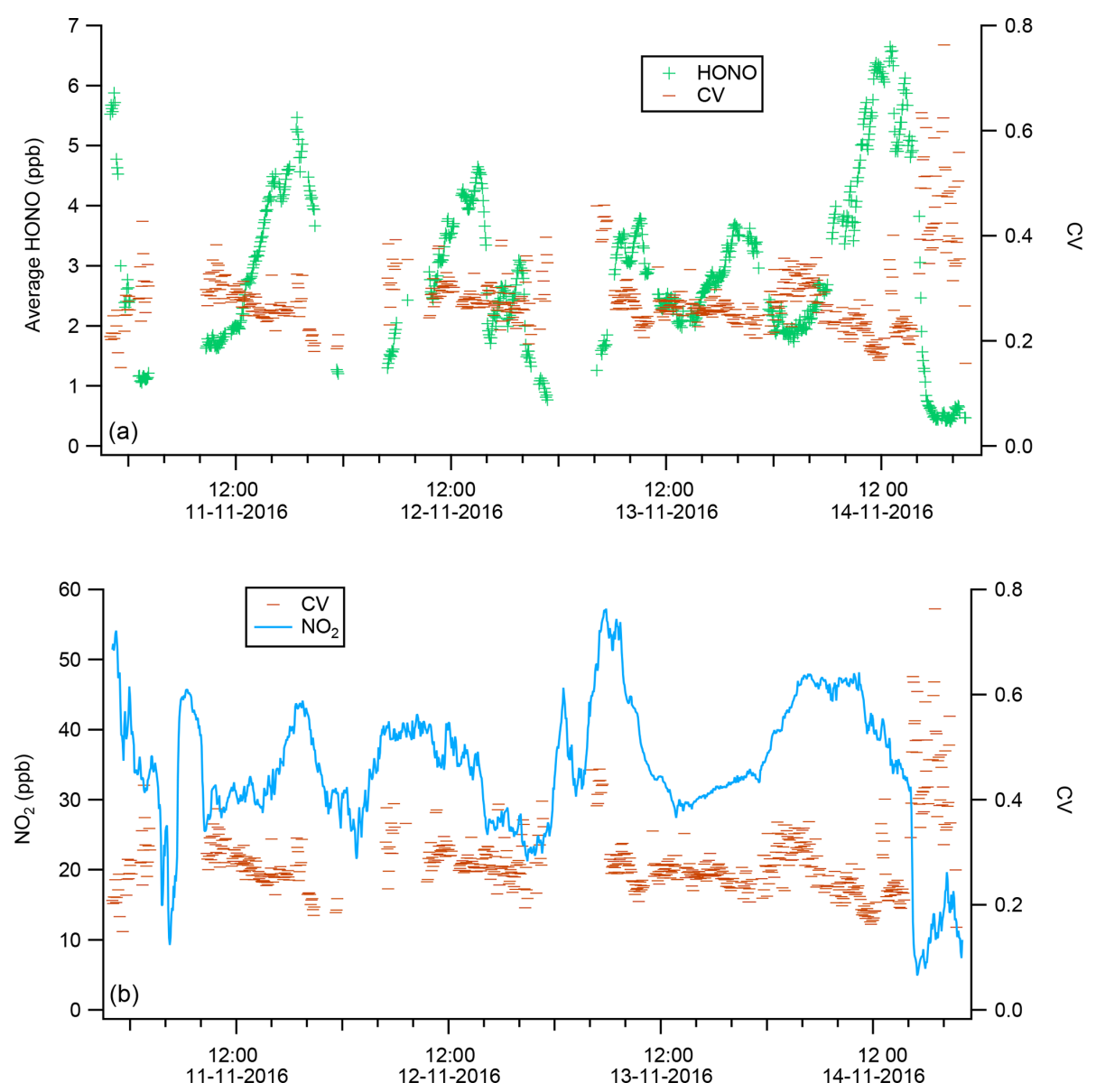

Figure 2. Time series of the coefficient of variance $(\mathrm{CV})$, mean mixing ratio of $\mathrm{HONO}(\mathbf{a})$ and $\mathrm{NO}_{2}$ (b) during the winter intercomparison. Time zone is local time, China standard time (CST). Note, only in the case in which all four instruments were measuring were the mean HONO and the CV calculated.

concentration (Fig. 3) to explore if ambient concentration or spatial heterogeneity could explain the disagreements. From Fig. 3, for all instrument pairs, the highest ND, and therefore largest relative difference between instruments, was at low HONO mixing ratios (ca. $<1 \mathrm{ppb}$ ) and was also associated with a westerly direction. At high wind speeds, the ND was also high between all instrument pairs (Fig. S6). As we observed high ND at relatively high wind speeds, it would suggest that spatial variability in ambient HONO concentrations did not affect the intercomparison as high wind speeds typically homogenize ambient concentrations from point and local sources. Overall from Figs. 3 and S5, the periods of low HONO concentration, high wind speeds and westerly winds all coincided during the formal winter intercomparison making it difficult to disentangle the influence of these factors on the observed ND.

\subsubsection{Instrument agreement at low concentrations}

There was evidence from the CV (Fig. 2) and ND (Fig. 3) analyses that the level of agreement between instruments de- creased at low HONO mixing ratios. Therefore, we applied RMA correlation analysis for periods when the HONO level was below $2 \mathrm{ppb}$ (as measured by CAM), and the results are shown in Table 4. From Table 4, the observed slopes between the BHAM-ICCAS-AIOFM at low concentrations $(<2 \mathrm{ppb})$ were similar to those for the whole winter intercomparison dataset (Table 2), unlike when compared to the CAM instrument. This suggests that the difference in measured concentrations between these instruments (BHAM-CAM-AIOFM, as indicated by the slope) was not related to concentration. The decrease in the slope for the low concentrations between CAM and the other three instruments compared to whole intercomparison (Tables 2 and 4, respectively), potentially points to changes in the CAM readings at lower concentrations. This change may be related to differences in instrument sensitivity (Table 1).

\subsection{Summer measurements}

While there was no formal intercomparison during the summer measurements, at the start of the summer measurements 
BHAM-ICCAS

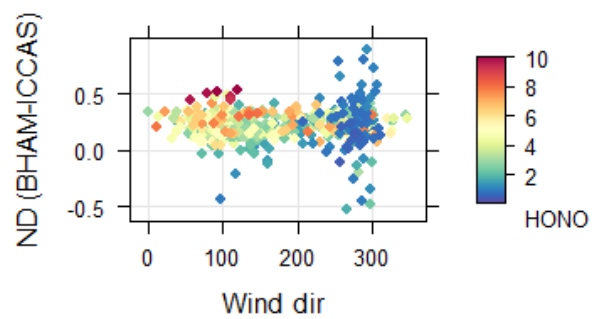

BHAM-CAM

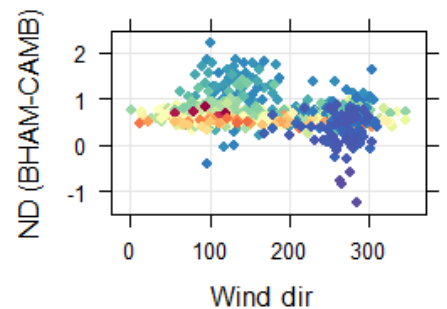

ICCAS-CAM
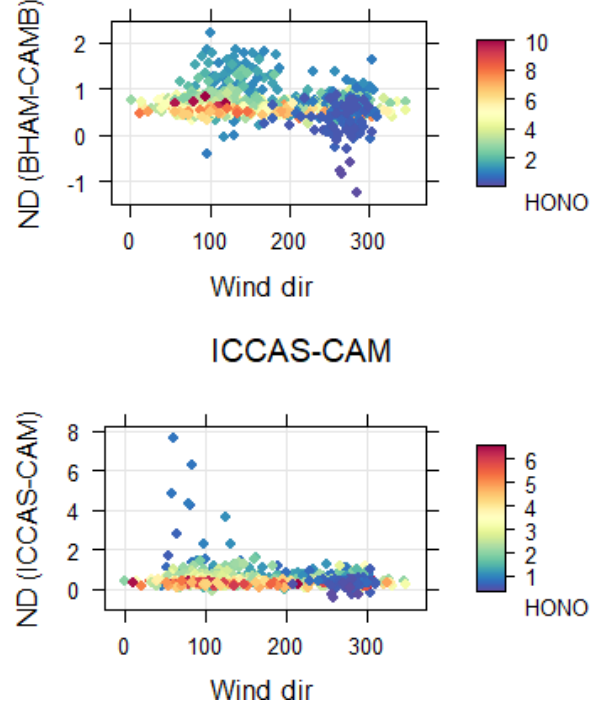

BHAM-AIOFM

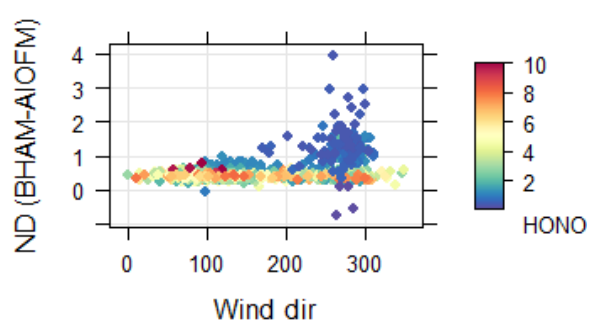

ICCAS-AIOFM

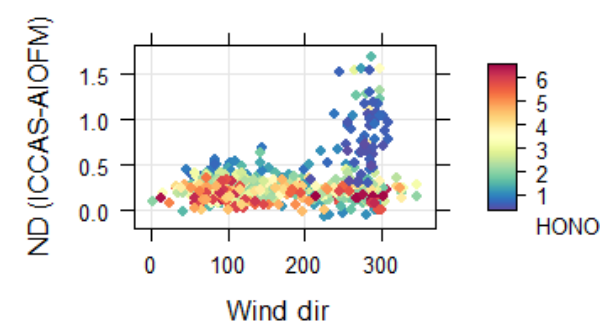

AIOFM-CAM

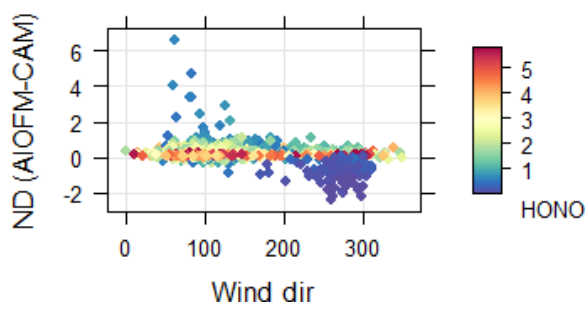

Figure 3. Normalized differences (ND) for each instrument pair as a function of wind direction coloured by measured HONO concentration for the winter intercomparison. Note the different scales for the $y$ axes and HONO abundance colour key.

Table 5. RMA regression relationships of HONO measured by BHAM-ICCAS-CAM during the co-located measurements at the start of the summer campaign (22-30 May 2017). All three inlet locations were the same as the formal winter intercomparison. Variability shown is the $95 \%$ confidence interval of the slope and intercepts.

\begin{tabular}{lrccc}
\hline Instruments & Intercept & Slope & $R$ & $N$ \\
\hline BHAM-ICCAS & $-0.24 \pm 0.02$ & $0.91 \pm 0.01$ & 0.97 & 2061 \\
BHAM-CAM & $-0.34 \pm 0.02$ & $0.61 \pm 0.01$ & 0.90 & 1233 \\
ICCAS-CAM & $0.21 \pm 0.02$ & $0.69 \pm 0.01$ & 0.85 & 1346 \\
\hline
\end{tabular}

the BHAM, ICCAS and CAM instrument inlets were colocated as per the winter formal intercomparison (Fig. S2). The relationship between instruments for this period is shown in Table 5. The agreement (gradient) between BHAM and ICCAS improved in the summer to 0.91 compared to winter (0.77) but with slight changes in intercept (Tables 2 and 5). A change was also observed between CAM and ICCAS with a lower slope observed for the start of summer (Table 5) compared to winter intercomparison period (Table 2).
The AIOFM instrument started measuring halfway through the summer campaign, and while the instrument was housed in the same container the inlet location was a few metres further from the other three instruments than in the winter intercomparison (Fig. S3). As a result, we compared the instrument readings for 1 week after the AIOFM instrument started measuring (7-14 June 2017), with the results shown in Table 6. Note during this period the CAM instrument had been moved to sample from the same container as AIOFM (Fig. S3). From Table 6, the agreement between instruments of the same type were within their stated uncertainties for the summer. However, when comparing the between the two different instrument types (wet chemical and BBCEAS, e.g. AIOFM-BHAM), the agreement was notably worse compared to the winter (Tables 2 and 6). The exception was that the agreement between the BHAM and CAM, which was similar in the winter and summer (Tables 2 and 5) despite the CAM inlet being further away from BHAM inlet (Table 6).

Generally, the level of agreement between instruments varied between the summer and winter, and this may reflect spatial variability in HONO concentrations as some of the in- 
Table 6. RMA regression relationships (with $95 \%$ confidence intervals) of HONO measured by all instruments in the middle of the summer campaign (7-14 June 2017). Note that BHAM and ICCAS inlets were in same location for this period. The CAM instrument had moved to the same container as AIOFM, whose inlets were $3 \mathrm{~m}$ apart. Variability shown is the $95 \%$ confidence interval of the slope and intercepts.

\begin{tabular}{lrccc}
\hline Instruments & Intercept & Slope & $R$ & $N$ \\
\hline BHAM-ICCAS & $0.17 \pm 0.04$ & $0.93 \pm 0.03$ & 0.90 & 900 \\
BHAM-AIOFM & $-0.18 \pm 0.03$ & $0.61 \pm 0.02$ & 0.81 & 1377 \\
BHAM-CAM & $0.02 \pm 0.03$ & $0.65 \pm 0.02$ & 0.86 & 1395 \\
ICCAS-AIOFM & $-0.08 \pm 0.02$ & $0.43 \pm 0.01$ & 0.81 & 1153 \\
ICCAS-CAM & $0.07 \pm 0.03$ & $0.53 \pm 0.02$ & 0.82 & 1167 \\
AIOFM-CAM & $0.20 \pm 0.01$ & $1.07 \pm 0.02$ & 0.92 & 1982 \\
\hline
\end{tabular}

strument inlet locations varied from summer to winter. In the summer, the CAM inlet moved closer to the AIOFM inlet, and the agreement between the two BBCEAS improved to be within uncertainty (Table 6). However, we also note that the BHAM and ICCAS inlets were in the same location in winter and summer, and yet the agreement between instruments changed considerably between the two measurement periods. We re-calculated the ND for two intercomparison periods analysed in the summer (Tables 4 and 5) and found no relationship between the ND and wind direction (Figs. S7 and S8). This suggests that during the summer measurements the wind direction may have exerted less influence on the spatial variability of the HONO levels or that the observed relationship between wind direction and ND in winter was associative not causal.

\subsubsection{Performance of MANC ToF-CIMS}

Measurements from the Manchester ToF-CIMS are compared to the BHAM and CAM instruments for the summer campaign as these instruments had the best data coverage for periods when the MANC instrument was measuring, as well as representing the typical upper and lower measurements (Fig. S9). In general the MANC instrument captured the temporal trends $(r>0.84)$ but recorded higher HONO concentrations than the other instruments (Table 7). Similar distributions were observed between the BHAM and MANC datasets, with the exception of a number of outliers for MANC (Fig. 4). We note that MANC was not co-located with either BHAM or CAM instrument and while this will likely have affected the intercomparison, the results do point to the MANC instrument capturing the temporal trends but at a higher concentration than the other instruments (157\%$239 \%$, Table 7).

\subsubsection{Performance of the YORK SIFT-MS}

The York SIFT-MS was primarily used for measuring VOC fluxes and so did not typically measure at ground
Table 7. RMA regression relationships of HONO measured by BHAM-CAMB-MANC for the whole summer period. Variability shown is the $95 \%$ confidence interval of the slope and intercepts.

\begin{tabular}{lrccc}
\hline Instruments & Intercept & Slope & $R$ & $N$ \\
\hline BHAM-MANC & $-0.35 \pm 0.06$ & $1.57 \pm 0.04$ & 0.84 & 1896 \\
BHAM-CAM & $0.00 \pm 0.02$ & $0.63 \pm 0.01$ & 0.84 & 4106 \\
CAM-MANC & $-0.30 \pm 0.05$ & $2.39 \pm 0.05$ & 0.88 & 2372 \\
\hline
\end{tabular}

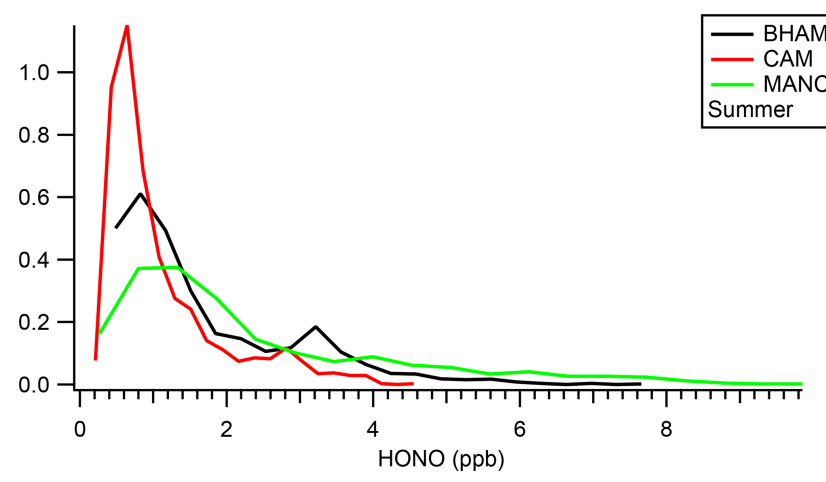

Figure 4. Histogram of measured summer concentrations (only for periods when all three instruments were measuring).

level. To enable an intercomparison with the other techniques, the YORK instrument measured at ground level, from 18:00 30 May until 09:00 China standard time (CST). 31 May 2017. The results are shown in Fig. 5, and while the short time period and spatial distance between inlets (approx. $50 \mathrm{~m}$ ) limits the conclusions that can be drawn, it is clear that the YORK instrument captured the temporal trends ( $r$ of $0.9-0.96$ compared to other techniques) and gave comparable concentrations to the BHAM instrument (slope of 0.78). Furthermore, we note that a co-located PTR-MS (PTR-TOR 1000 , Ionicon) was unable to see a HONO signal despite both instruments using $\mathrm{H}_{3} \mathrm{O}^{+}$to detect $\mathrm{HONO}$.

\section{Discussion}

From the literature, the recent intercomparison of ambient field measurements of HONO concentrations described by Pinto et al. (2014) is the most relevant to the current work. Overall, in their study Pinto and co-workers found that in general the level of disagreement between instruments was greater than the stated uncertainties for each instrument. While there was some evidence for a chemical interference (but Pinto and co-workers could not identify the compounds responsible definitively), there were additional factors that also appeared to affect the intercomparison. The best agreement in Pinto et al. (2014) was found for instruments with co-located inlets compared to instruments with inlets several metres apart and so points to spatial heterogeneity in HONO concentrations (possibly due a source on the roof surface) 


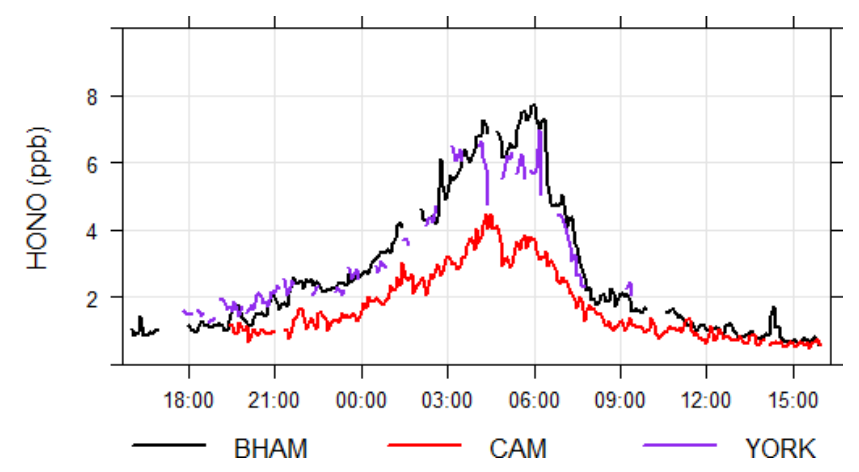

Figure 5. Time series for the period when the YORK instrument measured at ground level during the summer campaign.

affecting the intercomparison. Overall, the results from the current work are similar to those observed previously (Pinto et al., 2014), as there was a separation of up to $13 \mathrm{~m}$ between some instrument inlets, and this may have affected the results for the intercomparison in the current work. With respect to photolysis, the lifetime of HONO at midday ranged from 17-300 and 9-33 min for winter and summer, respectively (depending upon weather and/or cloud cover and/or aerosol loading) and may have contributed to spatial heterogeneity in HONO concentrations. However, in the current work the results do not conclusively point to spatial heterogeneity in HONO concentrations affecting the results. As both the current work and Pinto et al. (2014) found some evidence for spatial heterogeneity in HONO concentrations affecting the intercomparison, this would suggest that to avoid this issue future studies should use a common inlet for all instruments in the field.

Duan et al. (2018) presented results of an intercomparison at a rural site in China between a BBCEAS and a LOPAP, with good agreement observed (slope of 0.94 and $r^{2} 0.89$ ). The slope appeared to deviate from linearity above approximately $2 \mathrm{ppb}$, suggesting that at higher concentrations the relationship was changing, as observed here between CAM and wet chemical techniques (BHAM and ICCAS) (Tables 2 and 4). A divergence in the measured concentrations at high concentrations was also observed for all instruments as part of the FIONA intercomparison (Ródenas et al., 2013) but at much higher concentrations ( $>15 \mathrm{ppb}$ ) than most of those encountered here. However, we did not observe such a change in relationship at high and low concentrations between the AIOFM-BHAM-ICCAS, suggesting that this result was not related to instrument type. Furthermore, as the measurements from Duan et al. (2018) were performed in a rural site, conditions may also be a more homogenous mix compared to an urban location, and this may explain why there was better agreement between the LOPAP and BBCEAS in their study compared to the current work.

Throughout this work, the wet chemical techniques generally measured higher concentrations than the spectroscopic techniques, in agreement with previous studies (e.g. Stutz et al., 2010; Pinto et al., 2014). Pinto et al. (2014) suggested the possible cause may be a positive chemical interference in the wet chemical instruments. The observed dependence of the normalized difference between each instrument pair on wind direction may reflect changes in composition affecting the instrument readings. We note that the two-channel stripping coil used in the sampling inlet for both the BHAM and ICCAS instruments should account for any chemical interferences, particularly in the gas phase (Kleffmann et al., 2002). The aerosol in Beijing is typically acidic (Song et al., 2018) and based on the effective Henry's law constant for HONO we would expect there to be little particle-phase nitrite (Kleffmann et al., 2006). This combined with the expected low uptake of particles by the LOPAP sampling inlet (in order of $1 \%$ for particles with a diameter between 50-800 nm, Bröske et al., 2003) suggests that there would be limited chemical interference from particle-phase species. We also note that particle-phase chemical interference would likely be corrected for by the two-channel system.

In the current work, differences were observed between measurements from instruments of the same type (BBCEAS and wet chemical). The cause of this disagreement was difficult to pinpoint but may reflect differences in calibration and corrections applied by each group. In particular the BHAM and ICCAS instruments inlets were next to each other during the intercomparison $(<0.5 \mathrm{~m})$, and thus the differences likely reflect more differences in the operating conditions of the BHAM and ICCAS instruments. Both instruments used the same nitrite standard for calibration. Notably, there is a significant difference in DL between the instruments (Table 1) likely due to the different methodologies for determining baseline correction. For example, the BHAM instrument used zero air sampled at the inlet to determine the baseline, whereas ICCAS used water introduced into the wet chemical side of the instrument. Tests have shown that water results in a lower baseline measurement for the LOPAP (approx. 80-100 ppt). We note that the ambient HONO was typically within the parts per billion range during the intercomparison (Fig. 1), and the effect of this baseline difference would be negligible at these levels. But at lower concentrations (low $\mathrm{ppt}$ ), it would proportionally have a greater influence on the reported HONO levels by the BHAM and ICCAS instruments. High ND was observed at low concentration $(<1 \mathrm{ppb}$, Fig. 3), and the difference in absolute baseline correction may explain this.

The scaling factor to correct for the discrepancy in flow rate applied to the CAM instrument after the campaigns is unlikely to be the cause of the disagreement between the two BBCEAS. The two BBCEAS systems agree to within $\pm 10 \%$ for $\mathrm{NO}_{2}$ measurements, and the larger disagreement for HONO (13\%, Table 2) likely reflects higher spatial variability of ambient $\mathrm{HONO}$ compared to $\mathrm{NO}_{2}$, as the CAM and AIOFM inlets were the furthest apart during the formal winter intercomparison. The agreement between the two 
BBCEAS decreased at lower concentrations and this may reflect differences in DL (Table 1). The two BBCEAS instruments were found to be in better agreement in the summer compared to the winter. This may reflect the inlets being closer in summer compared to the winter, however there was still a distance of $3 \mathrm{~m}$ between inlets. We do not know the reasons why the agreement between the AIOFM and CAM instruments changed in the summer compared to winter. Whilst there were some variability in path length and purge flows between the two BBCEAS systems, these are not thought to account for the discrepancy as they did not vary winter to summer. Furthermore, another factor may be losses or production of $\mathrm{HONO}$ and $\mathrm{NO}_{2}$ on the inlet filter and/or tubing as these were naturally different across systems due to different residence times $(\sim 3$ and $\sim 0.5 \mathrm{~s}$ for the CAM and AIOFM BBCEAS, respectively). Laboratory tests using the same tubing material (Teflon) have however shown that neither the production nor the loss of HONO were significant in the CAM instrument (to less than a few percent) even at considerably longer inlet and cavity residence times, suggesting this was insignificant.

Generally, the agreement between instrument pairs varied from winter to summer, with the exception of CAM and BHAM instruments. As all instruments were operated and calibrated according to the same procedures in winter and summer, there were no changes in instrument operation that can explain these changes, and, as such, the cause is unclear. The concentrations observed during summer (mean of $1.2 \pm 0.9 \mathrm{ppb}(1 \sigma))$ were typically lower compared to the winter (mean of $2.35 \pm 1.9 \mathrm{ppb}(1 \sigma)$ ), and this may have affected the results.

\section{Conclusions}

Overall, from the winter intercomparison all instruments were found to agree on the temporal trends and variability in HONO $(r>0.97)$ yet displayed some divergence in absolute concentrations (slopes of $0.61-0.88$ ), with the wet chemical methods consistently somewhat higher than the BBCEAS systems. We found no evidence for any systematic bias in any of the instruments, with the exception of measurements near instrument detection limits. There was evidence that the relationship between some instruments varied for the different measurement periods (e.g. winter or summer), however the reason for this change was unclear. When considering the mass spectrometric methods (MANC ToF-CIMS and YORK SIFT-MS), these captured the temporal trends in HONO concentrations but were found to differ in absolute concentration relative to the other instrumentation.

There was no evidence for a definitive cause of systematic bias between the four instruments during the formal HONO intercomparison, which might justify scaling or excluding results from one or more instruments. As a result, we could not say with confidence, which instrument (if any) provided the "correct" measurement of HONO concentration. Therefore, to meet the needs of the wider APHH-Beijing programme for a single ground level HONO measurement, a merged HONO dataset was produced using the mean and range concentration of the four instruments that participated in the formal winter intercomparison (two wet chemical and two BBCEAS). This merged dataset will be used for future ground level analyses (e.g. model evaluation) across the APHH-Beijing programme.

Data availability. Original data are available on request from the authors and have been deposited in the (open access) CEDA repository, available for public download following the project embargo period.

Supplement. The supplement related to this article is available online at: https://doi.org/10.5194/amt-12-6449-2019-supplement.

Author contributions. The study was conceived by BO and LC. Measurements were performed by LC, LK, BO, JD, WZ, MS, AM, TB, SW, JA and AB. Formal analysis was performed by LC, LK and BO. All co-authors contributed to data curation. LC prepared the paper with contributions from all co-authors.

Competing interests. The authors declare that they have no conflict of interest.

Special issue statement. This article is part of the special issue "In-depth study of air pollution sources and processes within Beijing and its surrounding region (APHH-Beijing) (ACP/AMT interjournal SI)". It is not associated with a conference.

Acknowledgements. This work was funded by the UK Natural Environment Research Council (NERC), Medical Research Council and Natural Science Foundation of China under the framework of Newton Innovation Fund (NE/N007190/1 and NE/N007077/1). WJB, LJK and LRC acknowledge additional support by the UK NERC through the project Sources of Nitrous Acid in the Atmospheric Boundary Layer (SNAABL, NE/M013405/1). We acknowledge the support from Pingqing Fu, Zifa Wang, Jie Li and Yele Sun from IAP for hosting the APHH-Beijing campaign at IAP. We thank Zongbo Shi, Di Liu, Roy Harrison and Tuan Vu from the University of Birmingham; Siyao Yue, Liangfang Wei, Hong Ren, Qiaorong Xie, Wanyu Zhao, Linjie Li, Ping Li, Shengjie Hou, Qingqing Wang from IAP; Rachel Dunmore, Ally Lewis and James Lee from the University of York; Kebin $\mathrm{He}$ and $\mathrm{Xi}$ aoting Cheng from Tsinghua University; and James Allan and Hugh Coe from the University of Manchester for providing logistic and scientific support for the field campaigns. 
Financial support. This research has been supported by the UK Natural Environment Research Council (NERC), Medical Research Council and Natural Science Foundation of China (grant no. NE/N007190/1 and NE/N007077/1).

Review statement. This paper was edited by Jochen Stutz and reviewed by two anonymous referees.

\section{References}

Acker, K., Spindler, G., and Brüggemann, E.: Nitrous and nitric acid measurements during the INTERCOMP2000 campaign in Melpitz, Atmos. Environ., 38, 6497-6505, https://doi.org/10.1016/j.atmosenv.2004.08.030, 2004.

Acker, K., Möller, D., Wieprecht, W., Meixner, F. X., Bohn, B., Gilge, S., Plass-Dülmer, C., and Berresheim, H.: Strong daytime production of $\mathrm{OH}$ from $\mathrm{HNO}_{2}$ at a rural mountain site, Geophys. Res. Lett., 33, L02809, https://doi.org/10.1029/2005GL024643, 2006.

Appel, B. R., Winer, A. M., Tokiwa, Y., and Biermann, H. W.: Comparison of atmospheric nitrous acid measurements by annular denuder and differential optical absorption systems, Atmos. Environ. A.-Gen., 24, 611-616, 1990.

Arnold, J. R., Hartsell, B. E., Luke, W. T., Rahmat Ullah, S. M., Dasgupta, P. K., Greg Huey, L., and Tate, P.: Field test of four methods for gas-phase ambient nitric acid, Atmos. Environ., 41, 4210-4226, https://doi.org/10.1016/j.atmosenv.2006.07.058, 2007.

Bannan, T. J., Bacak, A., Muller, J. B. A., Booth, A. M., Jones, B., Le Breton, M., Leather, K. E., Ghalaieny, M., Xiao, P., Shallcross, D. E., and Percival, C. J.: Importance of direct anthropogenic emissions of formic acid measured by a chemical ionisation mass spectrometer (CIMS) during the Winter ClearfLo Campaign in London, January 2012, Atmos. Environ., 83, 301310, https://doi.org/10.1016/j.atmosenv.2013.10.029, 2014.

Bannan, T. J., Booth, A. M., Bacak, A., Muller, J. B. A., Leather, K. E., Le Breton, M., Jones, B., Young, D., Coe, H., Allan, J., Visser, S., Slowik, J. G., Furger, M., Prévôt, A. S. H., Lee, J., Dunmore, R. E., Hopkins, J. R., Hamilton, J. F., Lewis, A. C., Whalley, L. K., Sharp, T., Stone, D., Heard, D. E., Fleming, Z. L., Leigh, R., Shallcross, D. E., and Percival, C. J.: The first UK measurements of nitryl chloride using a chemical ionization mass spectrometer in central London in the summer of 2012, and an investigation of the role of $\mathrm{Cl}$ atom oxidation, J. Geophys. Res.-Atmos., 120, 5638-5657, https://doi.org/10.1002/2014JD022629, 2015.

Bannan, T. J., Le Breton, M., Priestley, M., Worrall, S. D., Bacak, A., Marsden, N. A., Mehra, A., Hammes, J., Hallquist, M., Alfarra, M. R., Krieger, U. K., Reid, J. P., Jayne, J., Robinson, W., McFiggans, G., Coe, H., Percival, C. J., and Topping, D.: A method for extracting calibrated volatility information from the FIGAERO-HR-ToF-CIMS and its experimental application, Atmos. Meas. Tech., 12, 1429-1439, https://doi.org/10.5194/amt12-1429-2019, 2019.

Bröske, R., Kleffmann, J., and Wiesen, P.: Heterogeneous conversion of $\mathrm{NO}_{2}$ on secondary organic aerosol surfaces: A possible source of nitrous acid (HONO) in the atmosphere?, At- mos. Chem. Phys., 3, 469-474, https://doi.org/10.5194/acp-3469-2003, 2003.

Carslaw, D. C. and Ropkins, K.: openair - An R package for air quality data analysis, Environ. Modell. Softw., 27-28, 52-61, https://doi.org/10.1016/j.envsoft.2011.09.008, 2012.

Cheng, P., Cheng, Y., Lu, K., Su, H., Yang, Q., Zou, Y., Zhao, Y., Dong, H., Zeng, L., and Zhang, Y.: An online monitoring system for atmospheric nitrous acid (HONO) based on stripping coil and ion chromatography, J. Environ. Sci., 25, 895-907, https://doi.org/10.1016/S1001-0742(12)60251-4, 2013.

Crilley, L. R., Kramer, L., Pope, F. D., Whalley, L. K., Cryer, D. R., Heard, D. E., Lee, J. D., Reed, C., and Bloss, W. J.: On the interpretation of in situ HONO observations via photochemical steady state, Faraday Discuss., 189, 191-212, 10.1039/C5FD00224A, 2016.

Duan, J., Qin, M., Ouyang, B., Fang, W., Li, X., Lu, K., Tang, K., Liang, S., Meng, F., Hu, Z., Xie, P., Liu, W., and Häsler, R.: Development of an incoherent broadband cavityenhanced absorption spectrometer for in situ measurements of $\mathrm{HONO}$ and $\mathrm{NO}_{2}$, Atmos. Meas. Tech., 11, 4531-4543, https://doi.org/10.5194/amt-11-4531-2018, 2018.

Febo, A., Perrino, C., Gherardi, M., and Sparapani, R.: Evaluation of a high-purity and high-stability continuous generation system for nitrous acid, Environ. Sci. Technol., 29, 2390-2395, 1995.

Febo, A., Perrino, C., and Allegrini, I. J. A. E.: Measurement of nitrous acid in Milan, Italy, by DOAS and diffusion denuders, Atmos. Environ., 30, 3599-3609, 1996.

Heland, J., Kleffmann, J., Kurtenbach, R., and Wiesen, P.: A New Instrument To Measure Gaseous Nitrous Acid (HONO) in the Atmosphere, Environ. Sci. Technol., 35, 3207-3212, https://doi.org/10.1021/es000303t, 2001.

Hera, D., Langford, V. S., McEwan, M. J., McKellar, T. I., and Milligan, D. B.: Negative Reagent Ions for Real Time Detection Using SIFT-MS, Environments, 4, 16, https://doi.org/10.3390/environments4010016, 2018.

Hou, S. Q., Tong, S. R., Ge, M. F., and An, J. L.: Comparison of atmospheric nitrous acid during severe haze and clean periods in Beijing, China, Atmos. Environ., 124, 199-206, https://doi.org/10.1016/j.atmosenv.2015.06.023, 2016.

Kennedy, O. J., Ouyang, B., Langridge, J. M., Daniels, M. J. S., Bauguitte, S., Freshwater, R., McLeod, M. W., Ironmonger, C., Sendall, J., Norris, O., Nightingale, R., Ball, S. M., and Jones, R. L.: An aircraft based three channel broadband cavity enhanced absorption spectrometer for simultaneous measurements of $\mathrm{NO}_{3}, \mathrm{~N}_{2} \mathrm{O}_{5}$ and $\mathrm{NO}_{2}$, Atmos. Meas. Tech., 4, 1759-1776, https://doi.org/10.5194/amt-4-1759-2011, 2011.

Kim, M. and Or, D.: Microscale $\mathrm{pH}$ variations during drying of soils and desert biocrusts affect $\mathrm{HONO}$ and $\mathrm{NH}_{3}$ emissions, Nat. Commun., 10, 1-2, 2019.

Kleffmann, J.: Daytime Sources of Nitrous Acid (HONO) in the Atmospheric Boundary Layer, Chem. Phys. Chem., 8, 1137-1144, https://doi.org/10.1002/cphc.200700016, 2007.

Kleffmann, J., Heland, J., Kurtenbach, R., Lorzer, J., and Wiesen, P.: A new instrument (LOPAP) for the detection of nitrous acid (HONO), Environ. Sci. Pollut. Res., 1, 48-54, 2002.

Kleffmann, J., Gavriloaiei, T., Hofzumahaus, A., Holland, F., Koppmann, R., Rupp, L., Schlosser, E., Siese, M., and Wahner, A.: Daytime formation of nitrous acid: A major source 
of $\mathrm{OH}$ radicals in a forest, Geophys. Res. Lett., 32, L05818, https://doi.org/10.1029/2005GL022524, 2005.

Kleffmann, J., Lörzer, J., Wiesen, P., Kern, C., Trick, S., Volkamer, R., Rodenas, M., and Wirtz, K. J. A. E.: Intercomparison of the DOAS and LOPAP techniques for the detection of nitrous acid (HONO), Atmos. Environ., 40, 3640-3652, 2006.

Le Breton, M., Bacak, A., Muller, J. B., Bannan, T. J., Kennedy, O., Ouyang, B., Xiao, P., Bauguitte, S. J. B., Shallcross, D. E., Jones, R. L., and Daniels, M. J.: The first airborne comparison of $\mathrm{N}_{2} \mathrm{O}_{5}$ measurements over the UK using a CIMS and BBCEAS during the RONOCO campaign, Analytical Methods, 6, 97319743, 2014.

Lammel, G. and Cape, J.: Nitrous acid and nitrite in the atmosphere, Chem. Soc. Rev., 25, 361-399, 1996.

Le Breton, M., Bacak, A., Muller, J. B., Bannan, T. J., Kennedy, O., Ouyang, B., Xiao, P., Bauguitte, S. J. B., Shallcross, D. E., Jones, R. L., and Daniels, M. J.: The first airborne comparison of $\mathrm{N}_{2} \mathrm{O}_{5}$ measurements over the UK using a CIMS and BBCEAS during the RONOCO campaign, 6, 9731-9743, 2014.

Le Breton, M., Bannan, T. J., Shallcross, D. E., Khan, M. A., Evans, M. J., Lee, J., Lidster, R., Andrews, S., Carpenter, L. J., Schmidt, J., Jacob, D., Harris, N. R. P., Bauguitte, S., Gallagher, M., Bacak, A., Leather, K. E., and Percival, C. J.: Enhanced ozone loss by active inorganic bromine chemistry in the tropical troposphere, Atmos. Environ., 155, 21-28, https://doi.org/10.1016/j.atmosenv.2017.02.003, 2017.

Le Breton, M., Wang, Y., Hallquist, Å. M., Pathak, R. K., Zheng, J., Yang, Y., Shang, D., Glasius, M., Bannan, T. J., Liu, Q., Chan, C. K., Percival, C. J., Zhu, W., Lou, S., Topping, D., Wang, Y., Yu, J., Lu, K., Guo, S., Hu, M., and Hallquist, M.: Online gasand particle-phase measurements of organosulfates, organosulfonates and nitrooxy organosulfates in Beijing utilizing a FIGAERO ToF-CIMS, Atmos. Chem. Phys., 18, 10355-10371, https://doi.org/10.5194/acp-18-10355-2018, 2018.

Lee, B. H., Wood, E. C., Herndon, S. C., Lefer, B. L., Luke, W. T., Brune, W. H., Nelson, D. D., Zahniser, M. S., and Munger, J. W.: Urban measurements of atmospheric nitrous acid: A caveat on the interpretation of the HONO photostationary state, J. Geophys. Res.-Atmos., 118, 2013JD020341, https://doi.org/10.1002/2013jd020341, 2013

Lee, B. H., Lopez-Hilfiker, F. D., Mohr, C.,Kurtén, T.,Worsnop, D. R., and Thornton, J. A.: An iodide-adduct high-resolution time of-flight chemical-ionization mass spectrometer: Application to atmospheric inorganic and organic compounds, Environ. Sci. Technol., 48, 6309-6317, https://doi.org/10.1021/es500362a, 2014.

Lee, J. D., Whalley, L. K., Heard, D. E., Stone, D., Dunmore, R. E., Hamilton, J. F., Young, D. E., Allan, J. D., Laufs, S., and Kleffmann, J.: Detailed budget analysis of HONO in central London reveals a missing daytime source, Atmos. Chem. Phys., 16, 2747-2764, https://doi.org/10.5194/acp-16-2747-2016, 2016.

Lopez-Hilfiker, F. D., Mohr, C., Ehn, M., Rubach, F., Kleist, E., Wildt, J., Mentel, Th. F., Lutz, A., Hallquist, M., Worsnop, D., and Thornton, J. A.: A novel method for online analysis of gas and particle composition: description and evaluation of a Filter Inlet for Gases and AEROsols (FIGAERO), Atmos. Meas. Tech., 7, 983-1001, https://doi.org/10.5194/amt-7-983-2014, 2014.

Michoud, V., Colomb, A., Borbon, A., Miet, K., Beekmann, M., Camredon, M., Aumont, B., Perrier, S., Zapf, P., Siour, G., Ait-
Helal, W., Afif, C., Kukui, A., Furger, M., Dupont, J. C., Haeffelin, M., and Doussin, J. F.: Study of the unknown HONO daytime source at a European suburban site during the MEGAPOLI summer and winter field campaigns, Atmos. Chem. Phys., 14, 2805-2822, https://doi.org/10.5194/acp-14-2805-2014, 2014.

Perner, D. and Platt, U.: Detection of nitrous acid in the atmosphere by differential optical absorption, Geophys. Res. Lett., 6, 917920, https://doi.org/10.1029/GL006i012p00917, 1979.

Pinto, J. P., Dibb, J., Lee, B. H., Rappenglück, B., Wood, E. C., Levy, M., Zhang, R.-Y., Lefer, B., Ren, X.-R., Stutz, J., Tsai, C., Ackermann, L., Golovko, J., Herndon, S. C., Oakes, M., Meng, Q.-Y., Munger, J. W., Zahniser, M., and Zheng, J.: Intercomparison of field measurements of nitrous acid (HONO) during the SHARP campaign, J. Geophys. Res.-Atmos., 119, 5583-5601, https://doi.org/10.1002/2013JD020287, 2014.

Priestley, M., le Breton, M., Bannan, T. J., Worrall, S. D., Bacak, A., Smedley, A. R. D., Reyes-Villegas, E., Mehra, A., Allan, J., Webb, A. R., Shallcross, D. E., Coe, H., and Percival, C. J.: Observations of organic and inorganic chlorinated compounds and their contribution to chlorine radical concentrations in an urban environment in northern Europe during the wintertime, Atmos. Chem. Phys., 18, 13481-13493, https://doi.org/10.5194/acp-1813481-2018, 2018.

Ren, X., Gao, H., Zhou, X., Crounse, J. D., Wennberg, P. O., Browne, E. C., LaFranchi, B. W., Cohen, R. C., McKay, M., Goldstein, A. H., and Mao, J.: Measurement of atmospheric nitrous acid at Bodgett Forest during BEARPEX2007, Atmos. Chem. Phys., 10, 6283-6294, https://doi.org/10.5194/acp-106283-2010, 2010.

Ródenas, M., Muñoz, A., Alacreu, F., Brauers, T., Dorn, H.-P., K1effmann, J., and Bloss, W.: Assessment of HONO measurements: The FIONA campaign at EUPHORE, in: Disposal of Dangerous Chemicals in Urban Areas and Mega Cities, Springer, 45-58, 2013.

Spanel, P. and Smith, D.: An investigation of the reaction of $\mathrm{H}_{3} \mathrm{O}^{+}$and $\mathrm{O}_{2}^{+}$with $\mathrm{NO}, \mathrm{NO}_{2}, \mathrm{~N}_{2} \mathrm{O}$ and $\mathrm{HNO}_{2}$ in support of selected ion flow tube mass spectrometry, Rapid Commun. Mass Spectrom., 14, 8, https://doi.org/10.1002/(SICI)10970231(20000430)14:8<646::AID-RCM926>3.0.CO;2-7, 2000.

Shi, Z., Vu, T., Kotthaus, S., Harrison, R. M., Grimmond, S., Yue, S., Zhu, T., Lee, J., Han, Y., Demuzere, M., Dunmore, R. E., Ren, L., Liu, D., Wang, Y., Wild, O., Allan, J., Acton, W. J., Barlow, J., Barratt, B., Beddows, D., Bloss, W. J., Calzolai, G., Carruthers, D., Carslaw, D. C., Chan, Q., Chatzidiakou, L., Chen, Y., Crilley, L., Coe, H., Dai, T., Doherty, R., Duan, F., Fu, P., Ge, B., Ge, M., Guan, D., Hamilton, J. F., He, K., Heal, M., Heard, D., Hewitt, C. N., Hollaway, M., Hu, M., Ji, D., Jiang, X., Jones, R., Kalberer, M., Kelly, F. J., Kramer, L., Langford, B., Lin, C., Lewis, A. C., Li, J., Li, W., Liu, H., Liu, J., Loh, M., Lu, K., Lucarelli, F., Mann, G., McFiggans, G., Miller, M. R., Mills, G., Monk, P., Nemitz, E., O’Connor, F., Ouyang, B., Palmer, P. I., Percival, C., Popoola, O., Reeves, C., Rickard, A. R., Shao, L., Shi, G., Spracklen, D., Stevenson, D., Sun, Y., Sun, Z., Tao, S., Tong, S., Wang, Q., Wang, W., Wang, X., Wang, X., Wang, Z., Wei, L., Whalley, L., Wu, X., Wu, Z., Xie, P., Yang, F., Zhang, Q., Zhang, Y., Zhang, Y., and Zheng, M.: Introduction to the special issue "In-depth study of air pollution sources and processes within Beijing and its surrounding region (APHH-Beijing)", At- 
mos. Chem. Phys., 19, 7519-7546, https://doi.org/10.5194/acp19-7519-2019, 2019.

Song, S., Gao, M., Xu, W., Shao, J., Shi, G., Wang, S., Wang, Y., Sun, Y., and McElroy, M. B.: Fine-particle $\mathrm{pH}$ for Beijing winter haze as inferred from different thermodynamic equilibrium models, Atmos. Chem. Phys., 18, 7423-7438, https://doi.org/10.5194/acp-18-7423-2018, 2018.

Sousan, S., Koehler, K., Thomas, G., Park, J. H., Hillman, M., Halterman, A., and Peters, T. M.: Inter-comparison of low-cost sensors for measuring the mass concentration of occupational aerosols, Aerosol Sci. Tech., 50, 462-473, https://doi.org/10.1080/02786826.2016.1162901, 2016.

Spataro, F. and Ianniello, A.: Sources of atmospheric nitrous acid: State of the science, current research needs, and future prospects, J. Air Waste Manage., 64, 1232-1250, https://doi.org/10.1080/10962247.2014.952846, 2014.

Spindler, G., Hesper, J., Brüggemann, E., Dubois, R., Müller, T., and Herrmann, H.: Wet annular denuder measurements of nitrous acid: laboratory study of the artefact reaction of $\mathrm{NO}_{2}$ with $\mathrm{S}$ (IV) in aqueous solution and comparison with field measurements, Atmos. Environ., 37, 2643-2662, 2003.

Stutz, J., Kim, E. S., Platt, U., Bruno, P., Perrino, C., and Febo, A.: UV-visible absorption cross sections of nitrous acid, J. Geophys. Res.-Atmos., 105, 14585-14592, https://doi.org/10.1029/2000jd900003, 2000.

Stutz, J., Oh, H.-J., Whitlow, S. I., Anderson, C., Dibb, J. E., Flynn, J. H., Rappenglück, B., and Lefer, B.: Simultaneous DOAS and mist-chamber IC measurements of HONO in Houston, TX, Atmos. Environ., 44, 4090-4098, https://doi.org/10.1016/j.atmosenv.2009.02.003, 2010.

Taipale, R., Ruuskanen, T. M., Rinne, J., Kajos, M. K., Hakola, H., Pohja, T., and Kulmala, M.: Technical Note: Quantitative long-term measurements of VOC concentrations by PTR-MS - measurement, calibration, and volume mixing ratio calculation methods, Atmos. Chem. Phys., 8, 6681-6698, https://doi.org/10.5194/acp-8-6681-2008, 2008.

Tong, S., Hou, S., Zhang, Y., Chu, B., Liu, Y., He, H., and Ge, M.: Exploring the nitrous acid (HONO) formation mechanism in winter Beijing: direct emissions and heterogeneous production in urban and suburban areas, Faraday Discuss., 189, 213-230, 2016.
Veitel, $\mathrm{H}$.: Vertical profiles of $\mathrm{NO}_{2}$ and $\mathrm{HONO}$ in the planetary boundary layer, doctoral dissertation, 2002.

Veres, P. R., Roberts, J. M., Wild, R. J., Edwards, P. M., Brown, S. S., Bates, T. S., Quinn, P. K., Johnson, J. E., Zamora, R. J., and de Gouw, J.: Peroxynitric acid $\left(\mathrm{HO}_{2} \mathrm{NO}_{2}\right)$ measurements during the UBWOS 2013 and 2014 studies using iodide ion chemical ionization mass spectrometry, Atmos. Chem. Phys., 15, 81018114, https://doi.org/10.5194/acp-15-8101-2015, 2015.

Voigt, S., Orphal, J., and Burrows, J. P.: The temperature and pressure dependence of the absorption cross-sections of $\mathrm{NO}_{2}$ in the $250-800 \mathrm{~nm}$ region measured by Fouriertransform spectroscopy, J. Photoch. Photobio. A, 149, 1-7, https://doi.org/10.1016/S1010-6030(01)00650-5, 2002.

Wang, J., Zhang, X., Guo, J., Wang, Z., and Zhang, M.: Observation of nitrous acid (HONO) in Beijing, China: Seasonal variation, nocturnal formation and daytime budget, Sci. Total Environ., 587-588, 350-359, https://doi.org/10.1016/j.scitotenv.2017.02.159, 2017.

Weber, B., Wu, D., Tamm, A., Ruckteschler, N., RodriguezCaballero, E., Steinkamp, J., Meusel, H., Elbert, W., Behrendt, T., Soergel, M., and Cheng, Y.: Biological soil crusts accelerate the nitrogen cycle through large $\mathrm{NO}$ and HONO emissions in drylands, P. Natl. Acad. Sci. USA, 112, 15384-15389, 2015.

Yang, Q., Su, H., Li, X., Cheng, Y., Lu, K., Cheng, P., Gu, J., Guo, S., Hu, M., Zeng, L., and Zhu, T.: Daytime HONO formation in the suburban area of the megacity Beijing, China, Science China Chemistry, 57, 1032-1042, 2014.

Zhou, W., Zhao, J., Ouyang, B., Mehra, A., Xu, W., Wang, Y., Bannan, T. J., Worrall, S. D., Priestley, M., Bacak, A., Chen, Q., Xie, C., Wang, Q., Wang, J., Du, W., Zhang, Y., Ge, X., Ye, P., Lee, J. D., Fu, P., Wang, Z., Worsnop, D., Jones, R., Percival, C. J., Coe, H., and Sun, Y.: Production of $\mathrm{N}_{2} \mathrm{O}_{5}$ and $\mathrm{ClNO}_{2}$ in summer in urban Beijing, China, Atmos. Chem. Phys., 18, 11581-11597, https://doi.org/10.5194/acp-18-11581-2018, 2018.

Zhou, X., He, Y., Huang, G., Thornberry, T. D., Carroll, M. A., and Bertman, S. B.: Photochemical production of nitrous acid on glass sample manifold surface, Geophys. Res. Lett., 29, 26-1, 2002 . 